\title{
ReaR
}

ISNN 19894090

Revista electrónica de AnestesiaR

\author{
FORMACIÓN MÉDICA
}

Julio 2020

\section{AT-121, ¿el opioide perfecto?}

Martín Orejas M, Martín Mora V.

Hospital Universitario Vall d'Hebron de Barcelona.

\section{Resumen}

Los opioides son los analgésicos más potentes y efectivos de que disponemos en la actualidad. Su cara oscura la encarna el creciente aumento de pacientes adictos a su consumo en todo el mundo, principalmente en Estados Unidos. Desde el descubrimiento de los primeros opioides sintéticos, la industria farmacéutica se halla en busca de un analgésico que no genere tolerancia ni dependencia, ni efectos adversos respiratorios.

La mayoría de los opiáceos son agonistas del receptor mu, cuya activación aumenta la disponibilidad sináptica de dopamina, neurotransmisor vehicular en circuitos de recompensa. Sin embargo, un cuarto receptor opioide ha sido descrito recientemente: el receptor de nociceptina/orfanina. Su activación inhibe la liberación de dopamina, evitando el refuerzo positivo que ocurre tras el consumo del fármaco. AT-121 es un agonista bifuncional MOP/NOP que ha sido probado en primates no humanos con resultados prometedores en cuanto a potencia analgésica, menores efectos secundarios sistémicos y menor tasa de adicción y abuso. Tales características hacen de esta molécula un arma esperanzadora en el tratamiento del dolor crónico o de la propia adicción a fármacos opioides. En los últimos años se han explorado distintos agonistas bifuncionales en roedores y primates no humanos con interesantes resultados; quedamos pues a la espera de futuras investigaciones en humanos.

\section{Introducción}

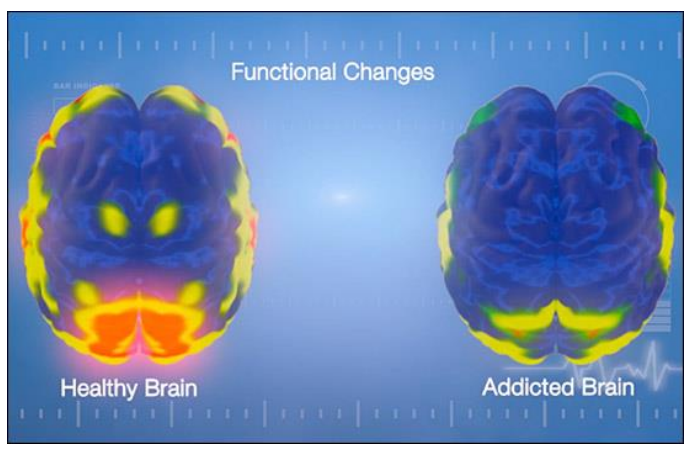

Los opioides son los analgésicos más potentes y efectivos de que disponemos en la actualidad. Su cara oscura la encarna el creciente aumento de pacientes adictos a su consumo en todo el mundo, principalmente en Estados Unidos. Desde el descubrimiento de los primeros opioides sintéticos, la industria farmacéutica se halla en busca de un analgésico que no genere tolerancia ni dependencia, ni efectos adversos respiratorios.

La mayoría de los opiáceos son agonistas del receptor $m u$, cuya activación aumenta la disponibilidad sináptica de dopamina, neurotransmisor vehicular en circuitos de recompensa. Sin embargo, un cuarto receptor opioide ha sido descrito recientemente: el receptor de nociceptina/orfanina. Su activación inhibe la liberación de dopamina, evitando el refuerzo positivo que ocurre tras el consumo del fármaco.

AT-121 es un agonista bifuncional MOP/NOP que ha sido probado en primates no humanos con resultados prometedores en cuanto a potencia analgésica, menores efectos secundarios sistémicos y menor tasa de adicción y abuso. Tales características hacen de esta molécula un arma esperanzadora en 
el tratamiento del dolor crónico o de la propia adicción a fármacos opioides. En los últimos años se han explorado distintos agonistas bifuncionales en roedores y primates no humanos con interesantes resultados; quedamos pues a la espera de futuras investigaciones en humanos.

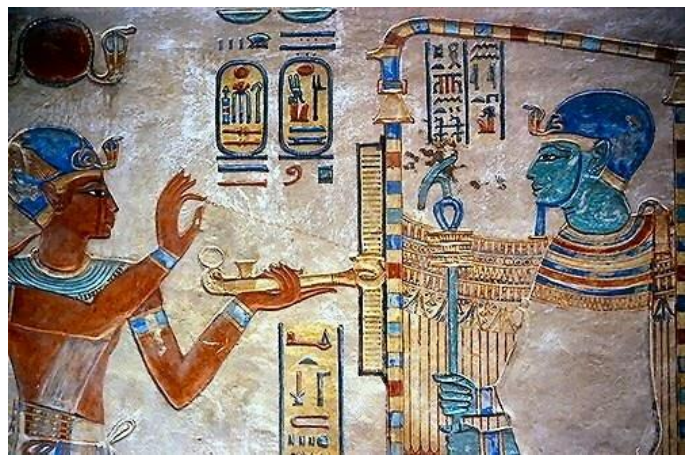

El opio, un extracto de la amapola Papaver somniferum, se ha usado durante siglos para aliviar el dolor y el sufrimiento. Los primeros datos de su cultivo datan de 3000-4000 años a.C. en la antigua Sumeria, desde donde se propagó a Europa y al resto de Asia.

Históricamente está documentado el uso de opio en distintas civilizaciones y épocas de la historia. Los egipcios utilizaron el opio para tratar las cefaleas del dios Ra. Galeno lo empezó a usar en el siglo II d.C. como analgésico y contra la disentería, y Paracelso creó el láudano en 1522 y lo llamó "piedra de la inmortalidad". En 1805, Sertumer logró la purificación de la morfina. Durante la Segunda Guerra Mundial, Ehrhart y Bockmühl desarrollaron la metadona. Más tarde apareció la heroína, en los años 70, junto con las primeras teorías sobre receptores opioides y ligandos endógenos.

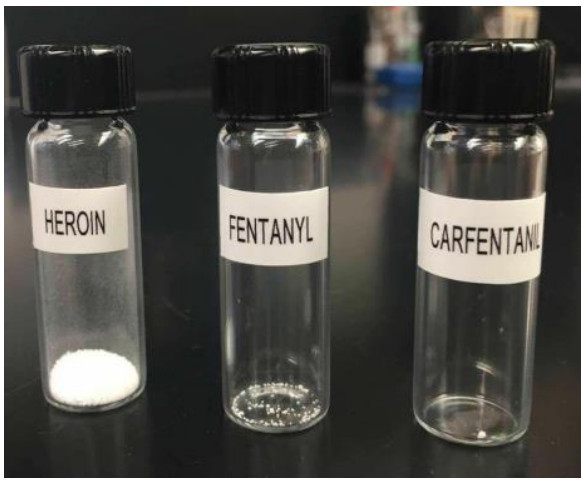

Pero el auge de la industria farmacéutica tuvo lugar principalmente en la última década del siglo XX, cuando surgieron los fármacos que utilizamos en nuestra práctica clínica habitual: fentanilo, remifentanilo, oxicodona, buprenorfina, hidromorfona, tramadol o tapentadol.

Los opioides son los analgésicos más potentes y efectivos disponibles en la actualidad. La mayoría de ellos son agonistas del receptor $m u$ (MOR, de las siglas en inglés $M u$ Opioid Receptor) (Tabla 1.). La activación de MOR, no solo posee efectos antinociceptivos, también aumenta la disponibilidad sináptica de dopamina, principal neurotransmisor en la creación de circuitos de recompensa. Este refuerzo positivo explica la epidemia mundial de adicción y abuso de opioides sintéticos, que afecta especialmente a los Estados Unidos.

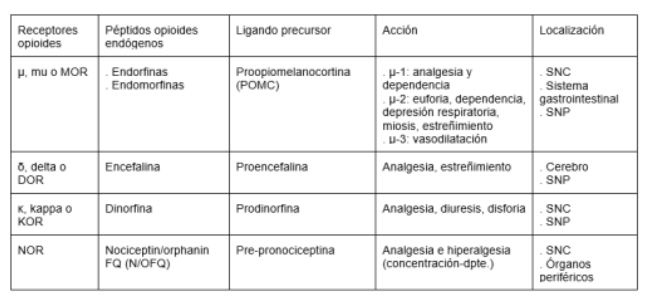

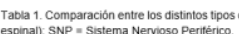




\section{Neurobiology of addiction:}

\section{NEUROBIOLOGY OF ADDICTION}

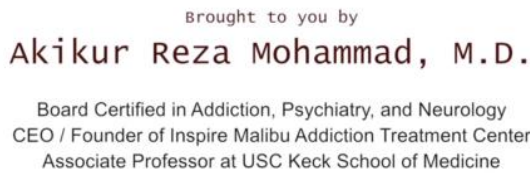

Brought to you by

Akikur Reza Mohammad, M.D.

Board Certified in Addiction, Psychiatry, and Neurology CEO / Founder of Inspire Malibu Addiction Treatment Center Associate Professor at USC Keck School of Medicine

\section{https://youtu.be/h9ZzmoiRxSQ}

En 1994, Mollereau et al. clonaron un cuarto tipo de receptor opioide con actividad homóloga a los receptores ya conocidos, el receptor del péptido nociceptina/orfanina (NOP, de las siglas en inglés Nociceptin/Orphanin Peptide). El receptor NOR y su ligando endógeno N/OFQ se expresan en el mismo circuito neuronal que el resto de receptores $\mathrm{y}$ ligandos opioides. A diferencia de éstos, NOR-N/OFQ inhibe la liberación de dopamina. Si no hay efecto recompensa, no se genera adicción: éste podría ser un aspecto clave en el tratamiento del dolor crónico y el manejo del abuso a opioides.

Existen diferencias importantes en la farmacocinética y farmacodinamia del sistema NOR-N/OFQ entre las distintas especies estudiadas (roedores, primates y humanos). En los estudios en roedores se ha relacionado este sistema con la aparición de hiperalgesia $y$ efectos anti-opioides a nivel supraespinal, aunque a nivel espinal puede producir analgesia. En primates no humanos, los agonistas selectivos de los receptores de NOP producen un efecto analgésico comparable al de la morfina, tanto a nivel central (espinal y supraespinal) como periférico, sin producir depresión respiratoria, ni hiperalgesia y tampoco "efecto recompensa" (potencial de abuso).
AT-121

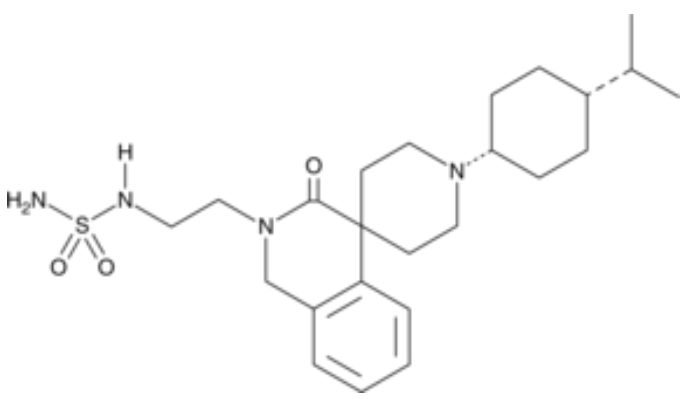

AT-121 es un agonista parcial bifuncional de NOP/MOP [con afinidad significativamente menor para los receptores delta (DOR) y kappa (KOR)]. Presenta una elevada potencia $\mathrm{y}$ efectividad debido al efecto sinérgico de la unión a ambos receptores. Tanto el bloqueo de MOR como el de NOR tiene propiedades antinociceptivas. En primates no humanos presenta efectos analgésicos similares a los de la morfina, aunque AT-121 es 100 veces más potente. Tiene un antagonista específico, J-113397, pero también responde a naloxona.

Ding $\mathrm{H}$, et al. demostraron en primates que, el patrón de abuso tras la administración repetida de AT-121 era diferente del que se presenta con otras sustancias (Fig. 1A y 1B). La evolución hacia la tolerancia y la dependencia podría ser más lenta con AT-121 que, con otros opiáceos, ya que atenúa el efecto recompensa (tanto de la propia molécula como de los mórficos), disminuyendo la necesidad del consumo. No se encontraron datos de hiperalgesia inducida por esta sustancia.
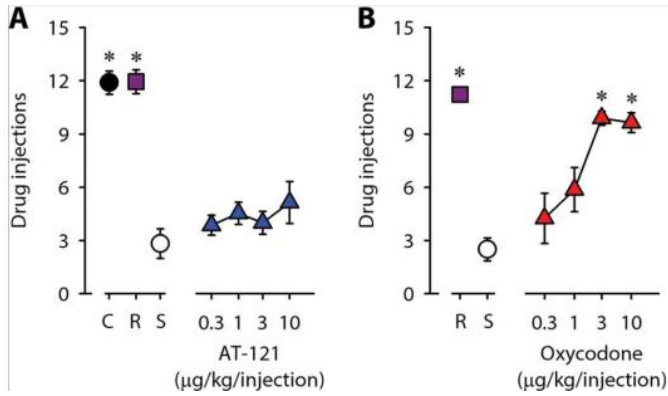

Fig. 1. Imagen extraída de Ding, et al. A bifunctional nociceptin and mu opioid receptor agonist is analgesic without opioid side effects 
in nonhuman primates. Sci Transl Med. 2018 Aug 29;10(456).

Comparación del "efecto recompensa" tras administración de diversos opioides: número de veces que el mono se inyecta el fármaco tras una primera exposición. Evaluación del potencial de abuso. Cocaína a $0,03 \mathrm{mg} / \mathrm{kg} / \mathrm{dosis}$, remifentanilo a $0,3 \mathrm{mcg} / \mathrm{kg} / \mathrm{dosis}$, solución salina a $\sim 0,14 \mathrm{ml} / \mathrm{kg} /$ dosis), AT-121 a 0,3-10 $\mathrm{mg} / \mathrm{kg} / \mathrm{dosis} u$ oxicodona 0,3-10 mg/kg/dosis. AT-121 y oxicodona: efectos diferentes en función de la dosis administrada.

Todas estas características podrían hacer de AT-121 un fármaco clave en el manejo de pacientes con dolor crónico.

Norikazu Kiguchi et al. describieron un agonista parcial de MOP/NOP denominado BU10038, con unas propiedades farmacocinéticas $\mathrm{y}$ farmacodinámicas similares a AT-121.

En los últimos años se han investigado distintos agonistas bifuncionales de NOP/MOP como AT-201, AT-212, cebranopadol o GRT6005, BU08028, etc. Los datos actuales indican que AT121 es un fármaco seguro: en primates una dosis de $0.03 \mathrm{mg} / \mathrm{kg}$ produce analgesia completa sin alterar la función respiratoria o la hemodinamia y sin variación del nivel de conciencia.

A la espera de futuras investigaciones en humanos, los resultados obtenidos hasta la fecha son esperanzadores.

\section{Bibliografía}

1. Ding et al., A bifunctional nociceptin and mu opioid receptor agonist is analgesic without opioid side effects in nonhuman primates. Sci Transl Med. 2018 Aug 29; 10(456): eaar3483. (HTLM)

2. Ding et al., A novel orvinol analog, BU08028, as a safe opioid analgesic without abuse liability in primates. PNAS September 13, 2016113 (37) E5511-E5518. (HTLM)

3. Kiguchi et al., BU10038 as a safe opioid analgesic with fewer sideeffects after systemic and intrathecal administration in primates. $\mathrm{Br} \mathrm{J}$ Anaesth 2019 Jun;122(6):e146e156. (PubMed)

4. Nurulain T. The Nociceptin Opioid Receptor (NOP) as a Therapeutic Target: Progress in Translation from Preclinical Research to Clinical Utility. J Med Chem. 2016 Aug 11; 59(15): 7011-7028 (HTML)

Correspondencia al autor

María Martín Orejas

mariaemeore@gmail.com

Residente de Anestesiología y Reanimación. Hospital Universitario Vall d'Hebron de Barcelona.

Víctor Martín Mora

v.martinmora72@gmail.com

Adjunto del Servicio de Anestesiología y Reanimación. Hospital Universitario Vall d'Hebron de Barcelona.

Aceptado para el blog en enero de 2020 